\title{
A CONTRIBUIÇÃO DOS ANIMAIS NAS AÇÕES DE SEGURANÇA PÚBLICA: REFLEXÕES SOBRE AMPLIAÇÃO DE FORÇAS LABORAIS
}

\author{
Luiz Ricardo dos Santos ${ }^{1}$
}

RESUMO: Há muito tempo os animais são importantes companheiros na mobilização de estratégias para os atos de Segurança Pública. Animais diversos como cachorros, cavalos - estes são os mais corriqueiros -, podem ser muito úteis para o auxílio às dinâmicas de proteção à sociedade. Este presente artigo tem, como objetivo, refletir sobre diversos aspectos que envolvem estas contribuições preciosas e os cuidados necessários que se devem ter no trato com estes animais, para que eles tenham ampla qualidade de vida, atenção às suas necessidades, e possam ter uma vida confortável nesta prática laboral. Pretende-se, com estas reflexões aqui norteadas, pautar estes aspectos temáticos que relacionam - se à boa prática de atenção aos animais, identificando, também, situações - problemas que precisam ser sempre pautas de reflexão e ação dos agentes e órgãos institucionais que atuam com estas colaborações.

Palavras - chaves: Animais. Segurança Pública. Qualidade de Vida. Comunidade. Educação.

\section{INTRODUÇÃO}

Os animas da Segurança Pública - ou, cães militares -, são preciosos ajudantes no ato laboral de defesa da comunidade, em diversas situações. Eles são treinados para o farejamento e a identificar localização de pessoas em situações de desastres, identificar drogas em compartimentos, ajudam a atacar malfeitores em situações de confronto. Nos atearemos, neste artigo, a reflexão do papel dos cães militares, mas, também podemos tecer reflexões sobre o papel dos animais equinos (cavalos) nesta prática de atendimento às demandas da população no que tange à segurança pública.

Desta forma, auxiliando os policiais em manutenção da ordem e vistorias, agilização para inserção em espaços de difíceis locomoção de veículos. São precisos

\footnotetext{
I Policial Militar na PMPR, Graduado em Administração de Empresas e Administração Rural, Pos graduado em Direito Ambiental, Direito Militar, Gestão em Logistica, Gestão Ambiental, Armazenagem de Grãos e Segurança Alimentar, Técnico em Segurança do Trabalho.
} 
colaboradores para a boa prática de defesa da população. Este processo de treinamento é minucioso e conta com médicos veterinários e adestradores especialistas que direcionam a capacitação destes animais para o real enfrentamento de situações adversas que irão enfrentar no decorrer do dia a dia laboral.

A preocupação destes profissionais que atuam na observação contínua sobre a qualidade de vida destes animais, bem como às metodologias para a sua formação específica, pairam por mecanismos pedagógicos de recompensa. É, em grande parte dos processos de adestramento, através das brincadeiras e ludicidade, com foco em recompensas, que estes animais vão ampliando os aspectos da percepção de sua atuação posterior e são formados. Entre estas metodologias, diversos instrumentos de aprendizagem são inseridos, como, por exemplo, as ações de repetição para memorização. Desde muito filhote, eles são treinados a desenvolver ampla habilidade no olfato, associando, por exemplo, o cheiro do brinquedo com a busca por diversos objetos como celulares, entorpecentes e explosivos.

Isso porque o instinto de caça e farejamento já é algo natural do animal. Portanto, nos cursos de formação, estas habilidades e competências são instigadas ao pleno desenvolvimento, trabalhando, desta forma, melhores instrumentais para a acoplagem à prática laboral da Segurança Pública, como, por exemplo, a Polícia Militar. São vários os tipos de animais inseridos nesta prática laboral, mas, há sempre uma espécie de observação para a linhagem dos animais. Se já tiverem pais que foram ou são especialistas neste tipo de trabalho colaborativo, acabam sendo mais priorizados. Genética, aspectos veterinário, linhagem, contam muito.

O uso destes animais nas ações da área da segurança é antigo. Primeiramente se faz necessário observar que o homem sempre teve uma relação próxima com os cães. Historicamente, nos memoriais e relatos históricos, eles sempre estiveram próximos, auxiliando-os mutuamente. Agora, mais contemporaneamente falando, os animais foram importantes instrumentos na primeira e na segunda guerra mundial, tecendo uma série de aproximações em trabalhos de combates. Raças como Pastor Alemão, Rottweiler e Dobermann popularizam-se neste período, pois além de serem usados no fronte de batalhas, eles também acabaram sendo vistos como grandes 
defensores da população frente às situações de perigo. Portanto, o período das guerras foi um histórico recorte temporal que ajuda a explicar a inserção destes animais como agentes de segurança e defesa, ampliando sua representação social no meio da população. Hoje, estes animais, além de domésticos e quase parte integrante de famílias, desempenham diversas funções, como, por exemplo: companhia, guia para deficientes visuais, guarda e proteção, salvamento, resgate, além de ações ostensivas de combate à criminalidade.

No âmbito da Segurança Pública, como destacado anteriormente, remete à uma série de contribuições, como, por exemplo, o faro de entorpecentes e explosivos, a busca por suspeitos, o resgate de desaparecidos e até mesmo cadáveres, o salvamento aquático. Como destacado, esta colaboração se faz presente e estratégico, em razão do fato de que em muitos estados há defasagem de profissionais das áreas de segurança pública. Portanto, estas colaborações, potencializam ainda mais as forças de segurança pública. A utilização de cães pelas Polícias Civil, Militar, Federal, Rodoviária Federal, Corpo de Bombeiros, Guardas Municipais é mais do que uma necessidade, tornando-se um reforço fundamental no combate à criminalidade, na proteção e salvamento de vidas.

Pode-se considerar esta colaboração dos animais como um equipamento não letal de defesa e proteção. Obviamente que se faz necessário observar que cada instituição precisa ter o seu arcabouço de regras e diretrizes para o uso dos animais como colaboradores deste tipo de ação de prevenção e ação. Há legislação firme e severa, em diversos estados e também no âmbito federal, com a ótica direcionada para esta e outras formas de uso dos animais. De acordo com especialistas, a mordida do cão militar não é letal, justamente por que há uma ação de preparação do mesmo para que ele obedeça as ordens de mordida e soltura, na medida em que o criminoso já esteja imobilizado.

Esta preparação perpassa, fundamentalmente, pelo viés psicológico, um dos aportes fundamentais para a preparação destes animais durante suas formações. A psicologia da comunicação é ferramenta constante desta preparação pois atua no direcionamento do controle dos sentidos, na obediência e da percepção, na atenção e 
na domínio da ação. Há diversos estudos e pesquisas que atentam-se à identificação dos fenômenos relacionados a este aspecto da condição de preparação, numa intersecção com a legislação e diretrizes que caminham no âmbito da qualidade de vida destes animais em atuação laboral na Segurança Pública, que atuam nas forças policiais trazendo mais segurança na operação, otimização do tempo, recursos e potencializando a eficácia, tanto da busca de drogas, de suspeitos, explosivos, etc.

Portanto, são diversas as contribuições do uso dos cães no âmbito da segurança pública. Em regiões fronteiriças, em que o contrabando e a entrada de entorpecentes ao território brasileiro são grandes desafios, a contribuição do animais é estratégica. A eficiência do trabalho de um cão policial, em vistoria de qualquer ambiente de difícil acesso ou de grande amplitude, como, por exemplo, carretas e ônibus que vêm de regiões de fronteira com outros países, permite um rápido resultado com os animais na fiscalização para encontrar algum ilícito nas abordagens (SAKATA, 2015).

Mas não é só isso. Entre as outras várias possibilidades de uso das habilidades do animais estão, também, a identificação de explosivos. Hoje, com a crescente manifestações de criminosos em explosões de caixas eletrônicos em bancos, este é, sem dúvida, uma importante ferramenta para os agentes de segurança, já que ao saírem às pressas do local invadido, muitos acabando deixando para traz verdadeiros arsenais prontos para explodirem. Os cães acabam auxiliando neste processo de identificação e solução, diante de suas habilidades de farejamento, já que a capacidade olfativa destes animais são muito superiores a de outros seres.

Frente à tão múltiplas funcionalidades dos cães policiais, demonstra-se, portanto, que a utilização deles se configura como um meio menos letal na repressão dos delitos. É mais efetivo e mais ágil o trabalho do policial, mais eficiente e com maior impacto psicológico em relação a outras ferramentas selecionadas pelo militar, devendo o policial minimizar os danos e lesões, respeitando e preservando a vida humana. Observamos, até o momento, a importância desta discussão sobre a inserção dos animais na prática laboral dos policiais e das forças de segurança pública. 
Se faz necessário, também, atentar-se para o viés mais humanizado no âmbito das relações entre o homem e o animal, que acabam tecendo laços e relações muito cordiais e próximas, de amizade, em toda a corporação. É por isso que eles têm um tratamento muito diferenciado, com manifestos de atenção e amor, visando a ampliação da qualidade de vida.

\section{O VIÉS LEGAL E O ASPECTO DA HUMANIZAÇÃO DE ATENDIMENTO: O POTENCIAL USO DOS ANIMAIS COMO ARMAS}

Este é um tópico importante e que perpassa pela análise de muitos especialistas que atuam diretamente na relação homem/animal. É fato e notório que estes animais, ao serem submetidos à situação de grande estresse e de conflitos que podem culminarem em violências e morte, acabam sendo aspectos que chamam a atenção sobre a qualidade de vida destes colaboradores. Sobre o viés reflete-se, portanto, que o uso de animais na atuação da segurança pública direciona-se a partir do serviço em atendimento à coletividade social, atendendo, inclusive, a missão da administração pública (que, no caso, engloba a segurança dos cidadãos). É uma forma de justificativa acerca da importante da união de forças para o combate à criminalidade. Considera-se assim que o poder de polícia é sobretudo necessário com vistas a auxiliar as ações que demandem as operações que abranjam cães (ROCHA, 2019).

Como mencionado anteriormente, o uso dos animais manifesta-se como uma arma de pequeno potencial letal. E isso se sustenta na legislação. Caracterizam-se como instrumento de menor potencial ofensivo as ações com pouca possibilidade de acarretar mortes ou lesões permanentes, reprimir, enfraquecer ou incapacitar provisoriamente as pessoas (BRASIL, 2014, art.4을. Este tipo de recurso deve ser utilizado pelos agentes de segurança pública, conforme a Lei $\mathrm{n}^{\mathrm{o}}$ 13.060, de 22 de dezembro de 2014, em casos em que não acarretar riscos aos policiais, fundamentando-se nos princípios da legalidade, necessidade, razoabilidade e proporcionalidade (BRASIL, 2014, art.2 $2^{\circ}$ ).

Isso quer dizer, na prática, que não se pode utilizar o uso de arma letal contra pessoas que estejam desarmadas. Certamente há de considerar exceções, quando há 
manifestação direta de risco à vida dos agentes e de terceiros que estejam nestas mesma localidades. E se houver casos assim, em que o agente precisa fazer o uso da força instrumental como arma para a proteção da própria vida e de terceiros, ao ferir o malfeitor, precisa chamar imediatamente os canais de atendimento médico, prestando socorro.

Neste sentido, os instrumentais que caracterizam-se como de menor potencial letal são diversos. Entre estes estão: cassetetes, gás lacrimogênio, spray de pimenta, eletrochoque e outras armas não letais. O cão é considerado um instrumento de menor potencial ofensivo e a sua aplicabilidade apropriada amolda-se na utilização diferenciada da força (ROCHA, 2019).

Para Clayton Marafioti Martins (2007) o cão, com seu faro apurado e sua lealdade, reúne potenciais estratégicos para a atuação em parceria com os agentes de segurança:

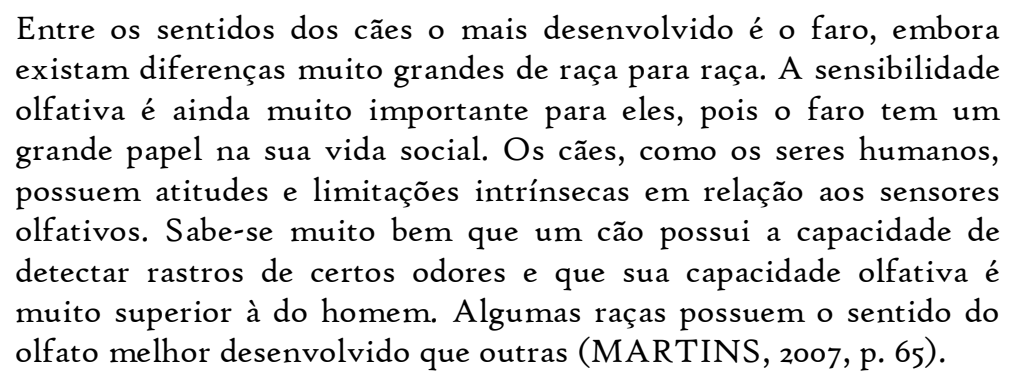

Este é um dos grandes diferenciais do animal no serviço da segurança. Já destacamos, anteriormente, sobre estes potenciais e habilidades. $O$ seu olfato poderoso pode diferenciar entre diversos odores, em específico a cocaína, maconha ou outra substância entorpecente, auxiliando, portanto, na identificação de criminosos. Para Sakata (2015), os animais podem também serem inseridos nas seguintes modalidades de atendimento:

- Policiamento ostensivo;

- Operações de busca, localização e resgate de pessoas perdidas;

- Demonstração de cunho educacional/recreativa;

- Policiamento em praças desportivas;

- Controle de distúrbios civis; 
- Contra guerrilha rural e urbana;

- Provas oficiais de trabalho e estrutura;

- Controle de rebelião e ou fuga de presos;

- Formaturas e desfiles de caráter cívico-militar;

- Deteç̧ão de entorpecentes (SAKATA, 2015, p. 186)

O autor lembra, ainda, que a depender do tipo de animal e sua estrutura física e habilidades pode-se desenvolver um tipo específico de atuação - patrulha, choque, guarda, faro, etc -. E todas estas funções - colaborações - requer além de habilidade conquistada com muito treino e preparação, também muita atenção no momento de atuação. Por exemplo: numa ação de deteç̧ão de explosivos, caso o orientador não dê comandos exato, pode-se provocar tragédias, inclusive tirando a vida do animal e do agente condutor.

É preciso sempre atenção à prudência e alta habilidade. Vale ressaltar que o adestramento policial torna o canino hábil e capacitado para determinada função técnica e tática, adaptando o comportamento genuíno do animal por meio de procedimento de ensinamento e treinamento, em conformidade com suas características individuais (ROCHA, 2009). Para cada ação ostensiva e planejamento de atuação policial que demande o uso dos animais, se faz necessário observar aquele tipo que mais se adequa a realidade exigida. Há tipos de animais que maior se comporta na mata (geralmente em busca de pessoas perdidas ou bandidos escondidos), ou na atuação de rua, ou em ambientes de desastres (identificando sobreviventes).

O que se percebe é que a atuação dos animais, cavalos, cães, e outros, ajudam a mobilizar frentes de defesas e ataques, prevenção e cuidados à população. No caso de nossa reflexão neste artigo, pairou-se, com maior acentuação, ao uso dos cães, que têm sido cada vez mais instrumento laboral nos órgãos de segurança pública.

\section{CONSIDERAÇÕES FINAIS}

Como destacado neste presente artigo, o objetivo desta reflexão foi direcionar um despertar do olhar para a presença dos animais, especialmente os cães, na vida 
laboral dos agentes de segurança pública. Como sabemos, o dever do Estado é garantir a proteção à sociedade, a ordem, os cuidados, a defesa da vida. Para isso, um policiamento ostensivo se faz presente nesta missão de ordem social e comunitária.

O cão se apresenta como uma ferramenta eficaz porque agiliza o trabalho, torna- o mais eficiente, reduzindo lesões e outros tipos de resultados de enfrentamentos não esperados. Durante a apresenta da reflexão deste artigo pode-se perceber, também, que o policial e demais agentes de segurança tem diretrizes, normas, regras, de ação e reação, que devem ser respeitados em detrimento das legislações apontadas sobre o dever deste profissional. Neste sentido, observamos a importância dos animais colaboradores que atuam na direta atuação de defesa da população.

Mas o artigo também expressou o tema por um outro viés: o da qualidade de vida destes animais que têm, em grande maioria, uma vida inteira de dedicação às forças de segurança pública, já que desde muito cedo, ainda filhotes, são levados à intensa capacitação, treinamento, preparação, desenvolvimento de habilidades e competências diversas, para a atuação em múltiplas ações. Não é todo animal, que realiza toda função.

As habilidades vão sendo construídas, aos poucos, a depender da raça e comportamento natural de cada animal, mas, também, a depender das metodologias aplicadas na formação destes animais. As corporações delimitam tempo de vida laboral destes cães militares que, na sequência, são aposentados, podendo viver com lares adotivos para que cuidem até o fim da vida. $O$ uso destes animais vem se configurando como meio menos letal na repressão dos delitos.

\section{REFERENCIAL BIBLIOGRÁFICO}

Curso Técnicas e Tecnologias Não-Letais de Atuação Policial, módulo I, SENASP/MJ, i8/ı/2007, pg. 05. Disponível em: <http://www.pf.gov.br/servicos$\mathrm{pf} /$ seguranca-privada/legislacao-normas-e-orientacoes/manual-do-

vigilante/manual-do-vigilante/Caderno\%20Didatico\%20CENL\%2oI.pdf >. Acessado em: 02 dez. 202I

DA ROSA, Leandro Edison. O emprego de Cães de Faro nas Operações de Fiscalização de Drogas Ilícitas Realizadas nos Postos da Polícia Militar Rodoviária 
de Santa Catarina. 2009. ııo f. Dissertação (Artigo Científico) - Polícia Militar do Estado de Santa Catarina, Florianópolis, 2009. Disponível em: $\langle$ http://www.pmrv.sc.gov.br/publicacoesETrabalhosArquivo.do?dPublicacao=2337>. Acesso em: 16 nov. 2021.

MARTINS, Clayton Marafioti; SOUZA, Claudionor de. Manual Cinotécnico: Emprego policial do cão. Polícia Militar de Santa Catarina, 2003. Acessado em: 〈http://www.pmrv.sc.gov.br/publicacoesETrabalhosArquivo.do?cdPublicacao=2337〉 . Acessado em or dez. 202I.

SAKATA, Marcus Vinícius Akira. O emprego do cão farejador no cumprimento de mandados de busca e apreensão pela polícia militar do estado de Mato Grosso. Revista Científica de Pesquisa em Segurança Pública, v.I4, n.I, p.I73-194, 2015. Disponível em: http://revistacientifica.pm.mt.gov.br/ojs/index.php/semanal/article/view/26o/pdf _I59. Acesso em: 25. Nov. de 2021.

ROCHA, Keila. Da Legalidade do Emprego de Cães nas Atividades Policiais. JusBrasil. 2019. Disponível em: https://keiladireito2or6.jusbrasil.com.br/artigos/528527316/da-legalidade-doempregode-caes-nas-atividades-policiais. Acesso em: 13. Mar. de 202I. 